\title{
Способ совернения незаконного оборота наркотических средств и психотропных веществ в исправительных учреждениях ФСИН России
}

Е. В. ЧЕРНЫШЕНКО - доцент кафедры уголовно-исполнительного права и организации воспитательной работы с осужденными юридического факультета ВИПЭ ФСИН России, кандидат юридических наук

P е ферат

В статье рассматриваются особенности совершения незаконного оборота наркотических средств и психотропных веществ в исправительных учреждениях ФСИН России. Автором были проведены исследование материалов уголовных дел по преступлениям рассматриваемого вида, а также анкетирование сотрудников учреждений уголовно-исполнительной системы, что позволило установить перечень 
наиболее распространенных способов совершения незаконного оборота наркотических средств и психотропных веществ. Выбор конкретного способа совершения преступления обусловливается рядом факторов: особенностями территории учреждений ФСИН России, установлением постоянного надзора за осужденными и их охраны, применением специальных сил и средств для обнаружения различных запрещенных предметов, в том числе наркотических средств и психотропных веществ. Следует отметить, что преступления данного вида чаще всего совершаются по предварительному сговору группой лиц, в составе которой находится осужденный, отбывающий наказание в исправительном учреждении и координирующий действия участников группы посредством средств мобильной связи. Незаконный оборот наркотических средств и психотропных веществ занимает лидирующую позицию в структуре пенитенциарной преступности и представляет огромную проблему для деятельности уголовно-исполнительной системы: он оказывает негативное воздействие на режим, оперативную обстановку и может спровоцировать совершение других, в том числе тяжких и особо тяжких, преступлений как против лиц, отбывающих наказание в виде лишения свободы, так и в отношении персонала учреждений. Всестороннее изучение способа совершения преступлений рассматриваемого вида позволяет вырабатывать эффективные способы противодействия и расследования.

Ключевые слова: исправительные учреждения; незаконный оборот наркотических средств и психотропных веществ; способ совершения преступления; осужденные, отбывающие лишение свободы; пенитенциарные преступления.

12.00.12 - Криминалистика; судебно-экспертная деятельность; оперативно-розыскная деятельность

\section{The method of committing illicit traffic in narcotic drugs and psychotropic substances in correctional facilities of the Federal Penal Service of Russia}

E. V. CHERNYSHENKO - Associate Professor of the Department of Penal Law and the Organization of Educational Work with Convicts of the Law Faculty of the Vologda Institute of Law and Economics of the Federal Penal Service of Russia

Abstract

The article discusses the peculiarities of the committing illicit traffic in narcotic drugs and psychotropic substances in correctional institutions of the Federal Penal Service of Russia. The author conducted a study of the materials of criminal cases on crimes of the type in question as well as a survey of employees of the penal system, which allowed us to establish a list of the most common ways of committing illicit traffic in narcotics and psychotropic substances. The choice of a specific method of committing a crime is determined by a number of factors: the features of the territory of the FSIN institutions of Russia, the establishment of constant supervision and protection of convicts, the use of special forces and means to detect various prohibited items, including narcotic drugs and psychotropic substances. It should be noted that crimes of this type are most often committed by prior conspiracy by a group of persons, which includes a convict serving a sentence in a correctional institution and coordinating the actions of group members by means of mobile communications. Illicit trafficking in narcotic drugs and psychotropic substances occupies a leading position in the structure of penal crime and poses a huge problem for the penitentiary system: it has a negative impact on the regime, operational environment and can provoke the commission of other crimes, including grave and especially grave ones such as against persons serving a sentence of imprisonment as well as against staff of institutions. A comprehensive study of the method of committing crimes of this type allows you to develop effective methods of counteraction and investigation.

Key words: correctional institutions; illicit trafficking in narcotic drugs and psychotropic substances; method of committing a crime; convicts serving imprisonment; penal crimes.

12.00.12 - Forensics; forensic activity; operational investigation 
Незаконный оборот наркотических средств и психотропных веществ в исправительных учреждениях представляет собой достаточно серьезную проблему для учреждений и органов ФСИН России. Так, за 2018 г. в учреждениях уголовно-исполнительной системы было зарегистрировано 225 преступлений рассматриваемого вида, что составило 25 \% от общей численности зарегистрированных преступных деяний, совершенных на территории исправительных учреждений [3, с. 20]. В результате проведенных обысков и досмотров было обнаружено и изъято 53 028,709 г наркотических средств и психотропных веществ [3, с. 36].

Незаконный оборот наркотических средств и психотропных веществ в исправительных учреждениях не только создает угрозу для охраняемых уголовным законом отношений, но и оказывает негативное влияние на режим, оперативную обстановку в учреждении в целом, а также может повлечь за собой совершение других правонарушений, в том числе преступлений. В связи с этим важным представляется вопрос своевременного обнаружения и пресечения совершения преступлений рассматриваемого вида. Огромное значение для этого направления деятельности имеют знания об особенностях механизма совершения незаконного оборота наркотических средств и психотропных веществ на территории исправительных учреждений, его криминалистической характеристике. Одним из элементов криминалистической характеристики любого преступления является способ его совершения. Выбор способа указывает на личность вероятного преступника. По мнению профессора Н. Г. Шурухнова, данные о способе преступления позволяют нам сформировать преставление о следах, оставленных в результате совершения преступления, месте их расположения, содержащихся в них сведениях о физических особенностях личности преступника и т. д. [5, с. 453]. Следовательно, лицо, производящее расследование, располагая информацией о способе совершения преступления, может сделать предположения о личности возможного преступника.

Исследователи интересующей нас криминалистической категории по-разному определяют способ совершения преступления, но многие сходятся во мнении, что это система или совокупность действий, направленных на подготовку, совершение, сокрытие преступного деяния, которая зависит от целей, окружающих факторов, лич- ности преступника, времени и места совершения преступления [1, с. 16-17; 2, с. 167].

Рассматривая способ совершения незаконного оборота наркотических средств и психотропных веществ в исправительных учреждениях, следует отметить, что в последние годы все чаще при организации такого рода преступлений используются средства мобильной связи. Осужденные добывают данные запрещенные предметы различными способами: прибегая к помощи родственников и близких, которые отправляют им посылки и передачи, прибывают на свидания, или посредством установления неслужебных связей с персоналом исправительных учреждений. За 2018 г. на территории учреждений ФСИН России было изъято 56355 средств мобильной связи и комплектующих к ним [3, с. 37].

Выбор способа совершения незаконного оборота наркотических средств и психотропных веществ на территории исправительного учреждения значительно отличается от соответствующего процесса за пределами данных учреждений. Обусловлено данное обстоятельство рядом факторов, в числе которых специфика деятельности самих учреждений ФСИН России, которые обладают режимной территорией, где установлены определенные требования, организована постоянная охрана и надзор, регулярно проводятся различные режимные мероприятия. Это вынуждает преступников избирать ухищренные способы сокрытия наркотических средств и психотропных веществ, подлежащих доставке и передаче осужденным, отбывающим лишение свободы.

Проведенные нами исследование материалов уголовных дел о незаконном обороте наркотических средств и психотропных веществ в исправительных учреждениях и опрос сотрудников учреждений позволили определить, что преступления рассматриваемого вида совершаются осужденными как единолично, так и в составе группы. При этом встречаются как контактные, так и бесконтактные способы передачи. К контактным способам нами отнесены:

- передача при проведении свиданий с родственниками и иными лицами (такой способ указали 58,5 \% опрошенных сотрудников);

- передача в момент нахождения осужденного за пределами исправительного учреждения, например при осуществлении работы на временном производственном объекте (указали 9 \% опрошенных); 
- передача во время встреч с сотрудниками правоохранительных органов, представителями общественных организаций и др. (отметили 33,6 \% опрошенных сотрудников);

- передача при этапировании (перемещении) осужденного (указали 27,3 \% опрошенных) [4, с. 45].

Бесконтактными способами можно считать:

- перебрасывание через основное ограждение исправительного учреждения, в том числе с использованием различных технических устройств, таких, например, как беспилотные летательные аппараты, ставшие очень популярными в последние годы (указали 41 \% опрошенных сотрудников);

- передачу в посылках, бандеролях, передачах (отметили 68,4 \% опрошенных) [4, c. 471 .

Наиболее распространенным способом совершения незаконного оборота наркотических средств и психотропных веществ в исправительных учреждениях, как показало проведенное нами исследование, является перебрасывание через основное ограждение. За 2018 г. в исправительных учреждениях было изъято 26 408,393 г наркотических средств и психотропных веществ, доставленных таким способом [3, с. 36]. Этот способ был установлен в 53,7 \% изученных уголовных дел по рассматриваемой категории преступлений. Так как рассматриваемый способ совершения преступлений требует определенных физических усилий, в большинстве случаев его избирают лица мужского пола. Для реализации преступного замысла, направленного на передачу наркотических средств или психотропныхвеществ осужденному, изготавливается сверток, внутри которого находится вещество, подлежащее передаче, для утяжеления к нему добавляется какой-либо груз. В качестве утяжелителя могут использоваться обычный камень или иные предметы, которые позволяют замаскировать сверток, чтобы при попадании на территорию учреждения он не вызывал подозрений у сотрудников. Например, в материалах изученных нами уголовных дел встретился случай, когда в качестве такого груза был использован клубень картофеля, внутри которого была оборудована полость, куда и поместили наркотическое средство. Клубень был переброшен через основное ограждение исправительного учреждения на территорию производственного участка, где не вызвал подозрений у сотрудников колонии. Впоследствии данный сверток был поднят осужденным, которому он предназначался.
Следует отметить, что в практике расследования рассматриваемого вида преступлений встречаются факты, когда к сверткам с наркотическими средствами или психотропными веществами прикрепляются фонарики небольших размеров, что облегчает поиск в случае перебрасывания в темное время суток. Так, например, сотрудники одной исправительной колонии задержали у основного ограждения учреждения гражданина Д., намеревавшегося перебросить сверток с наркотическим средством героин общей массой 200,24 г по просьбе своего знакомого осужденного 3., который отбывал наказание в данном учреждении. При досмотре задержанного при нем был обнаружен сверток с наркотическим средством, перемотанный липкой лентой, с прикрепленным к нему фонариком (Арх. Краснояр. район. суда Самар. обл. за 2011 г. Уголов. дело № 1-128/2011).

Избирая такой способ доставки наркотических средств или психотропных веществ, осужденные внимательно изучают территорию колонии, осуществляют выбор места наименьшего скопления персонала и других осужденных. Лицо, которое будет непосредственно осуществлять перебрасывание, уделяет внимание обследованию прилегающей к учреждению территории, анализирует регулярность и качество ее патрулирования.

Помимо того, что, как уже было сказано, для перебрасывания свертков с наркотическими средствами применяется физическая сила, преступники нередко прибегают к использованию различных технических устройств, которые позволяют значительно облегчить сам процесс доставки запрещенных предметов, а также осуществить перебрасывание, не приближаясь к основному ограждению и тем самым сокращая риск быть задержанными сотрудниками. В качестве таких технических средств используются арбалеты, беспилотные летательные аппараты, авиамодели и др.

Следующим способом совершения незаконного оборота наркотических средств и психотропных веществ в исправительных учреждениях является их передача в посылках, передачах и бандеролях, отправляемых в адрес осужденных, отбывающих лишение свободы. Такой способ был установлен нами в 20,2 \% изученных уголовных дел. Согласно положениям ст. 90 УИК РФ осужденные в исправительных учреждениях имеют право получать посылки, передачи и бандероли, количество которых будет зависеть от категории, к которой относится лицо, отбывающее наказание, вида учреждения и условий отбывания лишения свободы. Данную воз- 
можность используют близкие, родственники, знакомые осужденных с целью доставки тем наркотических средств и психотропных веществ посредством сокрытия во вложениях. Реализуя указанный способ доставки, преступники прибегают к различным ухищрениям, в числе которых:

- изготовление двойного дна или крышки в различных упаковках;

- пропитывание вещей и предметов наркотическим средством;

- сокрытие свертков в хлебобулочных изделиях;

- изготовление полостей в каблуках и подошвах передаваемой обуви и др.

Учитывая вышесказанное, успешное обнаружение наркотических средств и психотропных веществ возможно лишь при внимательном и профессиональном обследовании сотрудниками исправительных учреждений всех вложений посылок, передач и бандеролей, направляемых в адрес осужденных. Так, за 2018 г. благодаря квалифицированным действиям персонала учреждений и органов ФСИН России в посылках и передачах, поступивших осужденным, было обнаружено и изъято 2936,100 г наркотических средств и психотропных веществ, а в передачах - 4615,617 г [3, с. 36]. Так, например, осужденный У. по мобильному телефону договорился с гражданином А. о том, что тот приобретет для него в указанном осужденным месте наркотическое средство героин и передаст его во вложениях передачи через комнату приема и досмотра передач исправительной колонии строгого режима, расположенной в пос. Шексна Вологодской области. Однако преступный умысел не был реализован по независящим от осужденного У. и гражданина А. причинам ввиду того, что последний был задержан в ходе оперативно-розыскных мероприятий, проведенных сотрудниками исправительного учреждения, а наркотическое средство героин было обнаружено и изъято (Арх. Шексн. район. суда Вологод. обл. за 2011 г. Уголов. дело № 1-19/2011).

Еще одним довольно часто встречающимся способом доставки наркотических средств и психотропных веществ в исправительные учреждения является передача их во время проведения свиданий с близкими и родными. Как показывают данные статистики ФСИН России, в 2018 г. при проведении свиданий было обнаружено и изъято 2146,542 г наркотических средств и психотропных веществ [3, с. 36]. Указанный способ совершения преступления был использован в 7,3 \% изученных нами в ходе исследования уголовных дел. В исправительных учреждениях осужденным, отбывающим лишение свободы, согласно ст. 89 УИК РФ, предоставляются длительные и краткосрочные свидания с родственниками и иными лицами. Краткосрочные свидания проводятся под постоянным надзором со стороны администрации учреждений, в том числе с применением аудиовизуальных и иных технических средств контроля. Длительные же свидания проходят в специально отведенных для этого помещениях без присутствия персонала. Тем самым во втором случае создается довольно благоприятная обстановка для передачи осужденным любых запрещенных предметов, в том числе и наркотических средств, психотропных веществ. В связи с этим единственно допустимыми способами обнаружения предназначающихся для передачи запрещенных препаратов являются получение информации в ходе проведения оперативно-розыскных мероприятий, а также качественное производство обысков и досмотров при организации свиданий осужденных с родственниками и иными лицами.

Доставка наркотических средств и психотропных веществ указанным способом также требует от преступников определенной подготовки и сокрытия запрещенных предметов ухищренными способами, такими как:

- использование естественных полостей организма для помещения полимерных пакетов с запрещенным содержимым;

- сокрытие свертков на теле под одеждой, в подкладочной ткани различных предметов гардероба;

- сокрытие в вещах, которые разрешается проносить на свидания.

Отдельным, однако довольно редко встречающимся способом доставки наркотических средств и психотропных веществ в исправительные учреждения ФСИН России выступает передача во время проведения свиданий с защитниками, представителями общественных организаций, сотрудниками правоохранительных органов. Данный способ был установлен в 1,4 \% изученных нами уголовных дел. Следует отметить, что выбор такого способа совершения преступления не потребует от осужденного, а также лица, осуществляющего передачу наркотического средства или психотропного вещества, каких-либо значительных действий по подготовке. В частности, с целью предоставления свидания с защитником или встречи с представителем общественной организации осужденному необходимо подать заяв- 
ление на имя начальника исправительного учреждения. Выявление и пресечение преступных деяний, совершаемых таким способом, является достаточно проблемным и чаще всего успешно при получении оперативной информации и качественном проведении досмотра лица, прибывающего на свидание, а также обыска осужденного после его проведения.

При доставке наркотических средств и психотропных веществ родственниками, иными лицами, защитниками, представителями общественных организаций пронос на территорию исправительного учреждения запрещенных предметов осуществляется через контрольно-пропускной пункт, на котором надлежащим образом должны быть организованы мероприятия по досмотру как самих указанных лиц, так и предметов и вещей, с которыми они проходят на территорию.

Вместе с тем в исправительных учреждениях есть еще один способ доставки осужденным запрещенных предметов, в том числе и наркотических средств, психотропных веществ, - провоз, пронос через контрольно-пропускной пункт по пропуску транспортных средств. В 2,3 \% изученных нами уголовных дел был установлен именно он. В круг субъектов, которые будут осуществлять доставку таким способом, могут войти персонал учреждений, исполняющих наказание, иные лица, которые организуют, например, доставку продуктов питания или иных предметов на территорию исправительного учреждения, и т. д. Отметим, что рассматриваемый способ является довольно сложным для реализации ввиду того, что все транспортные средства, которые пропускаются на территорию учреждений, подлежат досмотру сотрудниками мест лишения свободы. В ходе данного мероприятия используются различные технические средства, инструменты, а также служебные собаки, которые обладают навыками отыскания различных запрещенных предметов, в том числе наркотических средств и психотропных веществ.

Провоз наркотических средств и психотропных веществ в салоне автомобиля требует от преступников применения различных ухищрений для их сокрытия. В частности, используются:

- сокрытие в обивке салона транспортного средства;

- маскировка под лекарственные препараты в автомобильной аптечке;
- провоз в личных вещах водителя, расположенных в салоне транспортного средства, или грузе, который доставляется в учреждение, и др.

Еще одним способом незаконного оборота наркотических средств и психотропных веществ в исправительных учреждениях выступает их передача или приобретение в момент нахождения осужденного за пределами учреждения. Указанный способ был установлен в 0,9 \% изученных уголовных дел. Следует отметить, что осужденные, находясь за пределами исправительного учреждения, могут приобретать наркотические средства и психотропные вещества, как прибегая к помощи третьих лиц, так и самостоятельно. При подготовке к совершению преступлений таким способом осужденные внимательно изучают деятельность сотрудников, осуществляющих пропускной режим на контрольно-пропускном пункте, и выясняют качество проводимых обысков и досмотров. В группу риска как способные воспользоваться рассматриваемым способом доставки наркотических средств и психотропных веществ входят, в первую очередь, лица, пользующиеся правом передвижения без конвоя или сопровождения в порядке применения ст. 96 УИК РФ. Данная категория осужденных выводится на работу и заводится в учреждение через контрольно-пропускной пункт, и в случае некачественного проведения личного обыска и досмотра вещей создается вероятность проноса на территорию запрещенных предметов. Так, например, осужденный Я., трудоустроенный в пекарне за пределами колонии-поселения, где он отбывал наказание, в ночное время, находясь в районе мусорной свалки, собрал коноплю, отделив при этом корни растений, и тем самым приобрел наркотическое средство марихуана массой не менее 35,82 г. Хранил данное наркотическое средство осужденный при себе без цели сбыта для личного употребления. Позже он попытался пронести собранную марихуану на территорию колонии-поселения, но в ходе обыска, проведенного сотрудниками учреждения, наркотическое средство было обнаружено и изъято (Арх. Богучан. район. суда Краснояр. края за 2012 г. Уголов. дело № 1-316/2012) .

Таким образом, обладая данными о способе совершения незаконного оборота наркотических средств и психотропных веществ в исправительных учреждениях ФСИН России, лицо, производящее расследование, 
может сделать предположение о личности вероятного преступника, а персонал учреждений и органов уголовно-исполнительной системы выработать систему мер по профилактике и предупреждению преступлений рассматриваемого вида.

\section{СПИСОК ЛИТЕРАТУРЫ}

1. Зуйков, Г. Г. Криминалистическое учение о способе совершения преступления / Г. Г. Зуйков // Социалистическая законность. - 1971. - № 11. - С. 14-19.

2. Куранова, Э. Д. Об основных положениях методики расследования отдельных видов преступлений / Э. Д. Куранова // Вопросы криминалистики. - 1962. - № 6-7. - С. 152-167.

3. Основные показатели деятельности уголовно-исполнительной системы за январь-декабрь 2018 г. : информационно-аналитический сборник. - Тверь : НИИИТ ФСИН России, 2019. - 328 с.

4. Чернышенко, Е. В. Расследование незаконного оборота наркотических средств и психотропных веществ в исправительных учреждениях ФСИН России : диссертация на соискание ученой степени кандидата юридических наук / Е. В. Чернышенко. - Вологда, 2014. - 234 с.

5. Шурухнов, Н. Г. Криминалистика / Н. Г. Шурухнов. - Москва : Юрист, 2003. - 639 с. - ISBN 5-7975-0536-3.

\section{REFERENCES}

1. Zujkov G. G. Kriminalisticheskoe uchenie o sposobe soversheniya prestupleniya [Forensic doctrine of the method of committing a crime]. Socialisticheskaya zakonnost' - Socialist rule of law, 1971, no. 11, pp. 14-19. (In Russ.).

2. Kuranova E. D. Ob osnovnyh polozheniyah metodiki rassledovaniya otdel'nyh vidov prestuplenij [On the main provisions of the methodology for the investigation of certain types of crimes]. Voprosy kriminalistiki - The forensics, 1962, no. 6-7, pp. 152-167. (In Russ.).

3. Osnovnye pokazateli deyatel'nosti ugolovno-ispolnitel'noj sistemy za yanvar'-dekabr' $2018 \mathrm{~g}$. [Key performance indicators of the penal system for January-December 2018]. Tver, 2019. 328 p. (In Russ.).

4. CHernyshenko E. V. Rassledovanie nezakonnogo oborota narkoticheskih sredstv i psihotropnyh veshchestv $v$ ispravitel'nyh uchrezhdeniyah FSIN Rossii. Diss. kand. yurid. nauk [Investigation of illicit trafficking in narcotic drugs and psychotropic substances in correctional facilities of the Federal Penal Service of Russia. Diss. PhD. in Law]. Vologda, 2014. 234 p. (In Russ.).

5. SHuruhnov N. G. Kriminalistika [Forensics]. Moscow, 2003. 639 p. (In Russ.). 